IBAD Sosyal Bilimler Dergisi

IBAD Journal of Social Sciences

dergipark.org.tr/ibad

IBAD, 2022; (12): 231-248

DOI: $10.21733 /$ ibad.990550

Özgün Araştırma / Original Article

\title{
Covid-19 Aşısı Olma Durumu ve Covid-19'dan Korunmanın Sağlık İnanç Modeli Bağlamında Değerlendirilmesi
}

\section{Evaluation of Covid-19 Vaccination and Protection from Covid-19 in the Context of Health Belief Model}

\section{Gülhan Gök ${ }^{*}$ \\ Ümmühan Güzel Baydoğan²}

\section{* Sorumlu yazar \\ Corresponding author}

${ }^{1}$ Öğretim Görevlisi, Amasya Üniversitesi, Türkiye Lecturer, Amasya University, Turkey gulhan.gok@amasya.edu.tr

ORCID ID https://orcid.org/0000-0003-4462-2541

${ }^{2}$ Doktora Öğrencisi, Frrat Üniversitesi, Türkiye

PhD. Student, Frrat University, Turkey ummuhannguzel@gmail.com

ORCID ID https://orcid.org/0000-0002-8608-3075

Makale geliş tarihi / First received : 03.10.2021

Makale kabul tarihi / Accepted : :28.10.2021

\section{Bilgilendirme / Acknowledgement:}

\section{Yazarlar așağıdaki billgilendirmeleri yapmaktadırlar:}

1- Bu araştırmaya tüm yazarlar aynı oranda katkı sağlamıştır. Ancak araştırma ve yayın sürecinin tamamı sorumlu yazar tarafından yürütülmüştür.

2- Makalenin yazarları arasında çıkar çatışması bulunmamaktadır.

3- Araştırmanın etik açıdan uygunluğu 08 Temmuz 2021 tarihinde toplanan Amasya Üniversitesi Girişimsel Olmayan Klinik Araştırmalar Etik Kurulu tarafından değerlendirilmiş ve etik açıdan uygun olduğuna oybirliği ile karar verilmiştir. Etik kurulun toplantı sayısı 7 ve karar nosu 120'dir.

4- Bu makalede araştırma ve yayın etiğine uyulmuştur.

This article was checked by Turnitin. Similarity Index 12\%

\section{Atıf bilgisi / Citation:}

Gök, G. \& Güzel Baydoğan, Ü. (2022). Covid-19 aşısı olma durumu ve Covid-19'dan korunmanın sağlık inanç modeli bağlamında değerlendirilmesi. IBAD Sosyal Bilimler Dergisi, (12), 231-248. 
ÖZ

Devletlerin varlığını istendik şekilde sürdürebilmesi, sağlıklı bir toplum yapısına sahip olmasıyla mümkündür. İçinde bulunduğumuz salgın döneminde bunu sağlayabilmek ancak aşı çalışmalarıyla olasıdır. $\mathrm{Bu}$ doğrultuda çalışmanın amacı “öğretmenlerin ve sağlık çalışanlarının Covid-19 aşısı olma durumunun belirlenmesi, aşıya ilişkin görüşlerinin tespit edilmesi, Covid-19 ve Covid-19 aşısına ilişkin algılarının neler olduğunun belirlenmesi"dir. Nicel araştırma tasarımında anket yönteminin kullanıldığı çalışma, durum tespitine yönelik ilişkisel tarama modelindedir. Araştırma kapsamında 517 kişiye ulaşılmıştır. Edinilen veriler istatistik programı aracılığıyla analiz edilmiştir. Bireylerin aşı olma durumunu etkileyen en önemli faktörün 'kendini korumak' olduğu belirlenmiştir. Gerçekleştirilen bağımsız örneklem t-Testi sonucunda Covid-19'a yakalanma durumuna göre Sağlık İnanç Modeli boyutlarında farklılık olmadığı görülmüştür. Yapılan One Way Anova Testi sonucunda Sağlık İnanç Modelinin tüm boyutları bakımından anlamlı farklılık olduğu bulunmuştur. Araştırmada, katılımcıların Covid-19 duyarlılığı ve Covid-19 aşısına ilişkin yarar alg1sı orta düzeydedir. Covid-19 aşısı olmaya ilişkin engel algıları düşüktür. Diğer taraftan Covid-19 aşısı olmaya ilişkin ipuçları sağlık çalışanlarında orta düzeyde, öğretmenlerde düşük düzeydedir.

\section{Anahtar kelimeler}

Covid-19, Aşı, Sağlık İnancı, Sağlık Çalışanları,

Öğretmenler

\section{ABSTRACT}

It is possible for states to continue their existence in the desired way if they have a healthy society structure. In the current epidemic period, it is possible to achieve this only with vaccine studies. In this direction, the aim of the study is to "determine the status of teachers and health workers to be vaccinated against Covid-19, to determine their views on the vaccine, and to determine what their perceptions are about the Covid-19 and Covid-19 vaccine". The study, in which the questionnaire method was used in the quantitative research design, is in the relational survey model for due diligence. Within the scope of the research, 517 people were reached. Obtained data were analyzed through statistical program. It has been determined that the most important factor affecting the vaccination status of individuals is 'self-protection'. As a result of the independent sample t-Test performed, it was seen that there was no difference in the dimensions of the Health Belief Model according to the status of catching Covid-19. As a result of the One Way Anova Test, it was found that there was a significant difference in all dimensions of the Health Belief Model. In the study, the Covid-19 sensitivity of the participants and the perceived benefit of the Covid19 vaccine is moderate. Perceptions of barriers to getting the Covid-19 vaccine are low. On the other hand, clues about getting a Covid-19 vaccine are moderate in health workers and low in teachers.

\section{Keywords}

Covid-19, Vaccine, Health Belief, Health Workers, Teachers 


\section{GíRIŞ}

Toplumsal değişmeler ve gelişmeler sonucunda büyüyen dünya, milletlerin birbirinden habersiz olduğu bir durumdan çıkarak küresel bir ortama dönüşmüştür. Bu durum ise küreselleşme kavramı ile ifade edilir. Küreselleşmeye göre dünya genelinde ekonomik, siyasal ve kültürel boyutlarda bütünleşme; öne sürülen fikirlerin, üretilen görüşlerin, geliştirilen teknolojilerin küresel düzeyde kullanılması; milli sınırların ötesine geçerek yeni ilişki ve etkileşimlerin yaşanması; dünyanın küçülmesi ile sınırların soyut anlamda ortadan kalkması söz konusudur (Balay, 2004, s. 62). Bu küreselleşmeye bağlı olarak insanlar, birbirlerinden bağımsız coğrafyalarda bulunsalar bile yapılan bir çalışmadan, gerçekleştirilen bir aktiviteden veya herhangi bir durumdan dolaylı ya da doğrudan yollarla etkilenir. Görülen bu etkiler, bazen olumlu bazen de olumsuz olabilmektedir. Bu olumsuz durumlar; savaşlar, siyasi çekişmeler, ekonomik rekabetler, hükmetme mücadelesi, etkilenen değil etkileyen taraf olma çabası, salgın hastalıklar ve benzeri olaylar olabilir. Bu olayların geçmişte pek çok örneği görülmekle beraber salgın hastalıklar konusunda şu an yaşadığımız ve en güncel olay koronavirüs hastalığ1 19'dur (Covid-19). Bu hastalığın 30 Ocak 2020'de DSÖ Acil Durum Komitesi tarafından, Çin ve uluslararası lokasyonlarda artan vaka bildirim oranlarına dayanılarak küresel bir sağlık acil durumu ilan edilmesiyle küresel boyutta bir salgın hastalık kavramı söz konusu olmuştur (Velavan ve Meyer, 2020, s. 278).

Neslin devamlılığı ve çağın gerekleri doğrultusunda günlük hayatın sürdürülebilmesi için bireylerin ruh ve beden bütünlüğüne ve sağlıklı olmaya ihtiyaçları vardır. Önemli olan hasta olduktan sonra tedavi arayışına girilmesi değil hasta olmadan önce hastalığa yönelik önleyici tedbirlerin alınmasıdır. Salgın hastalıklarla ilgili alınabilecek tedbirler arasında en fazla öne çıkan önlemin aşı olduğu görülmektedir. Aşılama programları aracılığıyla bulaşıcı hastalıkların yayılımının engellenmesi ve hastalık sonucunda ortaya çıabilecek ölümlerin ya da kalıcı sekellerin önlemesi amaçlanır. Aşılama çalışmaları sonucunda hem bireysel bağışıklık hem de bireysel aşılanma yoluyla toplumsal bağışıklık kazanılması sağlanır. Toplumda aşılı bireylerin sayısı ne kadar artarsa bulaş riski ve aşılanmamış bireylerin hastalık etkeni ile temas durumu o kadar azalır. Bu sayede ise hastalığın o toplumda görülme durumu seyrekleşir (Gür, 2019, s. 1). Bu nedenle Covid-19'u önlemek için bir aşının hızla geliştirilmesi küresel bir zorunluluk olarak ortaya çıkmış olup bu süreçte kritik bir öneme sahiptir. Çünkü düzenleyici ve tıbbi kararlar fayda/risk hesaplamalarına dayanır. Bu fayda/risk hesaplamalarının toplumda bulduğu karşılığın; aşının topluma yansıtılma şekli, insanlar tarafından nasıl görüldüğü, aşıyla ilgili bilgilerin kulaktan kulağa aktarılışı vs. durumlara da dayalı olarak aşının toplumsal kabulü ya da reddi ile sonuçlanabileceği söylenilebilir (Graham, 2020, s. 945).

Kişilerin sağlık davranışının inanç, değer ve tutumlarından etkilendiği düşüncesinin savunulduğu Sağlık İnanç Modeli (SİM)'ne göre bireylerin sorun olarak değerlendirdiği inanç, değer ve tutumlar belirlenebilirse sağllk eğitimi ve tedavi yöntemleri daha doğru şekilde saptanabilir. Çünkü bireyin sağlıkla ilgili davranışları; sağlığına verdiği değer, hastalık ve hastalığın sonuçlarına ilişkin inançlarından etkilenir (Gözüm ve Çapık, 2014, s. 230). Beş alt boyuttan oluşan Sağlık İnanç Modeli'nde algılanan duyarlılık kavramı ile bireylerin sağlıklarının tehdit altında olması durumunda bu tehdit halini nasıl algıladıkları ve kendilerini risk altında görme durumları tanımlanır (Sağlam ve Tavman, 2021, s. 679). Diğer bir alt boyut olan ciddiyet algısı ise hastalığın tedavisinin reddedilmesi durumunda ortaya çıkabilecek olumsuz sonuçların algılanması ile ilgilidir (Kurcer ve Erdoğan, 2020, s. 465). Bu boyut genel 
manada bireylerin tıbbi bilgi düzeyleri ile ilişkili olmakla birlikte hastanın hastalıklarla alakalı daha önceki tecrübelerine dayalı olarak da şekillenebilmektedir (İbici Akça, 2021, s. 16). Oluşabilecek bir hastalık riski karşısında bireyin hastalık riskini önlemek veya riski azaltmak için önerilen davranışın yaratacağı olumlu sonuçlara yönelik algısı, SİM'deki bir diğer alt boyut olan yarar algısı kavramı ile ifade edilir (Kırılmaz ve Doğanyiğit, 2021, s. 202). Hasta tarafından hastalık tehdidinin azaltılacağı durumların bilinmesine rağmen yapılacak eylem, uygulanacak tedavi yolu; zahmetli, acı verici, pahalı bulunarak davranış benimsenmeyebilir. $\mathrm{Bu}$ süreçte davranış değişikliğinde etkili olan algı, engel algısıdır (İbici Akça, 2021, s. 17). Bireyler tarafından davranışları tetikleyebilecek ipuçlarına yönelik kavramlar, önerilen sağlık davranışının kabul edilmesi için karar verme sürecini tetikleyen uyaranlar, eyleme yönelik ipucu olarak kavramsallaştırılır (Champion ve Skinner, 2008). Bu bağlamda SİM ile bireyin sağlığı ve hastalığı ile ilgili problemleri algılaması, tedaviye ilişkin uyumsuzluğa neden olan faktörler, uyguladıkları sağlık davranışları ve bir sağlık davranışının gerçekleştirilmesini kolaylaştıran durumlar belirlenmeye çalışılır (Aydoğar Takcı ve Yıldırım, 2021, s.74; Kurcer ve Erdoğan, 2020, s. 465). Bireylerin Covid-19 hastalığ1 ve aşısına ilişkin görüşlerinin de SİM bağlamında değerlendirilmesinin, hastalığın ciddiye alınma, aşının yararlı bulunması, hastalığa karşı duyarlılık, aşı olma istekliliği ve aşı olmaya ilişkin algıladıkları engellerin belirlenmesinde araştırmacılara bir yol gösterici olacağı söylenilebilir.

İçinde bulunduğumuz salgın döneminde ön plana çıkmış olan Covid-19 aşılama çalışmalarının da SİM kavramıyla alakalı olarak nicel anlamda etkilendiği varsayılabilir. Ülkemizde 23 Temmuz 2021 tarihli verilere göre aşılama oranı \%26'dır (Our World in Data, 2021). Bu oran dikkate alındığında ülkemizdeki aşılama çalışmalarının nüfusa kıyasla henüz yeterli seviyeye ulaşmadığı söylenebilir. Diğer taraftan hizmet sektöründe çalışanların önemli bir bölümünü oluşturan ve toplumla sürekli etkileşim halinde bulunmak durumunda olan sağlık çalışanları ve öğretmenler, aşılama çalışmalarında öncelikli gruplar arasında yer almıştır (Gürbüz vd., 2021, s. 53; Yıldırım Baş, 2021, s. 248). Toplumun temel yapı taşlarından olan sağlık çalışanlarının ve eğitim sektörü çalışanlarının hizmetlerini kendilerinin ve çevrelerindeki bireylerin sağlık durumlarını riske atmadan sürdürebilmeleri için salgına yönelik tedbirlerini almış olmaları gereklidir. Bu tedbirler her ne kadar maske, mesafe, temizlik gibi kavramlarla vurgulansa da esas olan koruyucu niteliği yüksek ve daha kalıc1 çözüm sunan bir aşı uygulamasıdır (Haleem vd., 2020, s. 78; Kazak vd., 2020, s. 572; Parıldar, 2020, s. 20). Şu an ülkemizde kullanılan iki aşı türü mevcuttur: Almanya menşeili BioNTech ve Çin menşeili Sinovac (Yavuz, 2020, s. 233). Aşılama faaliyetlerinin başlangıcında tedarik sorunları nedeniyle tek seçenek söz konusu iken şu an da hangi aşının uygulanacağı tamamen bireylerin tercihine bırakılmış olup aşı yaptırma gönüllülük esasına dayalı durumdadır (Ülman, 2020, s. 369). Bu bağlamda hem aşılara ilişkin algının değerlendirilmesi hem de tercih edilme ve edilmeme durumlarının tespit edilmesi aşılanma oranlarının arttırılmasında önemli bir unsur olarak değerlendirilebilir.

Konu ile alakalı olarak yapılan literatür taramasında SİM ile çalışmalar arasında Covid-19 salgınından korunmada sağlık çalışanlarında kişisel koruyucu ekipman kullanımı (Korkmaz vd., 2021), öğretmenlerin ve okul yöneticilerinin salgına yönelik bireysel hazırlık algılarının incelenmesi (Kaya vd., 2021), diyabet hastalarının bakım inançları (Olgun ve Akdoğan Altun, 2012), kendi kendine ilaç kullanımı (Kırılmaz ve Doğanyiğit, 2021) ve öğretmenlerin kolorektal kanserden korunmaya yönelik sağlık inançlarının belirlenmesi (Aykaç Koçak ve Tümer, 2022) gibi çalışmaların yer aldığı görülür. Covid-19 hastalığıyla ilgili literatürdeki çalışmalara 
bakıldığında ise Covid-19 üzerine öğretmen adaylarının görüşleri (Görgülü Arı ve Hayır Kanat, 2020), Covid-19 sürecindeki uzaktan eğitime ilişkin öğretmen görüşlerinin incelenmesi (Demir ve Özdaş, 2020), Covid-19 ile ilgili öğretmen algılarının belirlenmesi (Cömert ve Şahin Çakır, 2021), Covid-19 aşısının kabulünde etkili olan faktörlerin belirlenmesi (Malik vd., 2020), Covid-19 aşısı geliştirme (Graham, 2020) ve Covid-19 aşısı geliştirme süreçleri (Wu, 2020) gibi çalışmalara rastlanır. Diğer taraftan sağlık çalışanlarının ve öğretmenlerin toplumla sürekli etkileşim halinde ve risk altında olmaları, aynı zamanda toplumu etkileyen bir kesimi temsil etmeleri bakımından bu iki kitlenin aşılara yönelik düşüncelerinin, aşı çalışmalarına yaklaşımlarının, tercih durumlarının, tercih etme ya da etmeme sebeplerinin belirlenmesi de son derece önemlidir. Bu bağlamda gerçekleştirlen araştırma ile sağlık çalışanlarının ve öğretmenlerin Covid-19'a yakalanma ve aşı olma durumlarının, aşı olma ya da olmama nedenlerinin, oldukları veya olmayı düşündükleri aşı türünün, aşı tercihlerinde etkili olan değişkenlerin belirlenmesi; Sağlık İnanç Modeli boyutlarının (Duyarlılık Algısı, Ciddiyet Algısı, Algılanan Yarar, Algılanan Engel, Eyleme Yönelik İpucu) meslek değişkenine, Covid19'a yakalanma ve Covid-19 aşısı olma durumuna göre analiz edilmesi amaçlanmıştır. Elde edilen veriler doğrultusunda alana yönelik öneriler sunularak gelecekte yapilacak olan çalışmalarda araştırmacılara katkı sağlanması ve aynı zamanda Covid-19 aşılarına ilişkin toplumsal bir bakışın ortaya konulması istenmiştir.

Araştırmanın amacı doğrultusunda oluşturulan H0 hipotezi ve araştırma soruları aşağıdaki gibidir:

Ho: Meslek değişkeni, Covid-19'a yakalanma durumu ve Covid-19 aşısı olma durumu ile Sağlık İnanç Modeli alt boyutları arasında anlamlı bir farklılık yoktur.

Araştırma soruları;

H1a: Meslek değişkeni ile Covid-19 duyarlılığı arasında anlamlı bir farklılık var mıdır?

Hıb: Meslek değişkeni ile Covid-19 ciddiyet algısı arasında anlamlı bir farklılık var mıdır?

Hı: Meslek değişkeni ile Covid-19 aşısını yararlı bulma durumu arasında anlamlı bir farklılık var midır?

Hıd: Meslek değişkeni ile Covid-19 aşısı olmaya ilişkin algılanan engel durumu arasında anlamlı bir farklılık var mıdır?

$\mathrm{H}_{1 e}$ : Meslek değişkeni ile eyleme yönelik ipuçları arasında anlamlı bir farklılık var mıdır?

H1f: Covid-19'a yakalanma durumu ile Covid-19 duyarlılığı arasında anlamlı bir farklılık var midir?

H1g: Covid-19'a yakalanma durumu ile Covid-19 ciddiyet alg1sı arasında anlamlı bir farklılık var midir?

H1h: Covid-19'a yakalanma durumu ile Covid-19 aşısını yararlı bulma durumu arasında anlamlı bir farklılık var midır?

H1ı: Covid-19'a yakalanma durumu ile Covid-19 aşısı olmaya ilişkin algılanan engel durumu arasında anlamlı bir farklılık var mıdır?

$\mathrm{H}_{11:}$ Covid-19'a yakalanma durumu ile eyleme yönelik ipuçları arasında anlamlı bir farklılık var midır? 
H1j: Covid-19 aşısı olma durumu ile Covid-19 duyarlılığı arasında anlamlı bir farklılık var midir?

Hık: Covid-19 aşısı olma durumu ile Covid-19 ciddiyet algısı arasında anlamlı bir farklılık var midir?

Hı: Covid-19 aşısı olma durumu ile Covid-19 aşısını yararlı bulma durumu arasında anlamlı bir farklılık var midır?

H1m: Covid-19 aşısı olma durumu ile Covid-19 aşısı olmaya ilişkin algılanan engel durumu arasında anlamlı bir farklılık var midır?

Hın: Covid-19 aşısı olma durumu ile eyleme yönelik ipuçları arasında anlamlı bir farklılık var midir?

\section{YÖNTEM}

\section{Araştırmanın Tipi}

$\mathrm{Bu}$ araştırmada, nicel yaklaşımlardan tarama deseni ve anket yöntemi kullanılmıştır. Araştırma tanımlayıcı nitelikte olup araştırmanın modeli, durum tespitine yönelik ilişkisel tarama modelidir. Aynı zamanda araştırma belirli bir süreyi içermesi nedeniyle süre bakımından kesitsel, araştırma kapsamında katılımcı bireylere ilişkin veriler kullanıldığı için analiz düzeyi bakımından ise bireysel bir araştırma niteliği taşır.

\section{Araştırmanın Evreni ve Örneklemi}

Sağlık Bakanlığı 2019 yılı istatistiklerine göre Türkiye'deki toplam sağlık personeli sayısı 1.033.767'dir ve 2021 yılı itibariyle aktif öğretmen sayısı 1148.514' tür (Sağlık Bakanlığı, 2019; Kasap, 2020).

$\mathrm{Bu}$ bağlamda araştırma evreni 1.033 .767 sağlı personeli ve 1.148 .514 öğretmenden oluşur. Pandemi sürecinde olunmasından dolayı araştırma verileri, dijital ortamlar aracilığıyla ulaşılan katılımcılardan elde edilmiştir. Araştırmanın sosyal platformları (facebook, whatsapp, instagram vb) kullanan katılımcılarla gerçekleştirilmiş olması nedeniyle örnekleme yöntemi olarak kolayda örnekleme yöntemi kullanılmıştır. Veri toplama sürecinde 270 öğretmene ve 247 sağlık çalışanına ulaşılabilmiştir. Araştırma kapsamında toplamda 517 katılımcıdan elde edilen veriler analiz edilmiştir.

\section{Verilerin Toplanması ve Veri Toplama Araçları}

Araştırma kapsamında, araştırmacilar tarafından oluşturulan anket formu ve Griptan Korunmaya Yönelik Sağlık İnanç Modeli Ölçeği kullanılmıştır. Oluşturulan anket formunda iki bölüm yer almaktadır. Anket formunun birinci bölümünde katılımcllara ait demografik özelliklerin belirlenmesi amacıyla 6 soru ve katılımcıların Covid-19 aşısıyla ilgili görüşlerini belirlemeye yönelik 6 soru olmak üzere toplam 12 soru bulunmaktadır.

Anket formunun ikinci bölümünde ise Erkin (2010) tarafından Türkçeye uyarlaması yapılan 'Gripten Korunmaya Yönelik Sağlik İnanç Modeli Ölçeği' gerekli iznin de sağlanması ile çalışmada kullanılmıştır. Ölçek ilk olarak meme kanseri taramalarında kullanılmak üzere 1984 yılında Champion tarafından dört boyutlu olarak geliştirilmiştir. Daha sonra Blue ve Valley (2002) tarafından geliştirilerek yedi boyutlu bir ölçek haline getirilmiştir (Erkin, 2010, s. 38). Türkçeye uyarlanan ve güvenirlik geçerlilik çalışması yapılan ölçek formunun yeni yapısı ise 
29 ifade ve 5 (Duyarlılık Alg1sı -8 önerme, Ciddiyet Alg1sı -4 önerme, Algılanan Yarar-6 önerme, Algilanan Engel-8 önerme ve Eyleme Yönelik İpuçlar1-3 önerme) boyuttan oluşmaktadır. Ölçeğin önermeleri 5'li Likert tipinde olup ifadeler 'Kesinlikle Katılmıyorum (1)''Kesinlikle Katıliyorum (5)' şeklinde derecelendirilmiştir.

Araştırmanın etik açıdan uygunluğu 08 Temmuz 2021 tarihinde toplanan Amasya Üniversitesi Girişimsel Olmayan Klinik Araştırmalar Etik Kurulu tarafından değerlendirilmiş ve etik açıdan uygun olduğuna oybirliği ile karar verilmiştir. Etik kurulun toplantı sayısı 7 ve karar nosu 120'dir. Veri toplama süreci gerekli tüm izinlerin alınmasından sonra başlatılmıştır.

\section{Verilerin Analizi}

Anket yöntemi ile toplanan veriler bir paket program (SPSS) ile analiz edilmiştir. Araştırmada kullanılan ölçeğin güvenirliğinin belirlenmesinde iç tutarlılık katsayısı (Croncbach's Alpfa) hesaplanmıştır. Ölçek alt boyutlarının ve ölçek genelinin Croncbach's Alpfa katsayısı değerleri şu şekildedir: Duyarlılık alg1sı alt boyutu, 0,772; ciddiyet alg1Sı alt boyutu, 0,794; algılanan yarar alt boyutu, 0,872; algilanan engel alt boyutu, 0,826; eyleme yönelik ipuçları alt boyutu, 0,683 ve ölçek geneli, 0,830'dur. Croncbach's Alpfa katsayısı değerlerinin 0,60'ın üzerinde olduğu görülmektedir. Bu değerler doğrultusunda ölçeğin güvenilir olduğu anlaşılmaktadır (Gürbüz ve Şahin, 2017, s. 127).

Araştırma kapsamında katılımcların demografik özelliklerinin ve Covid-19 aşısına ilişkin düşüncelerinin dağılımları, aşı olma durumlarına ve aşı tercihinde etkili olan unsurlara ilişkin dağılımlar, aşı olma ve aşı olmama nedenlerine ilişkin dağılımlar hesaplanmıştır. Ölçek verilerinin analizinde öncelikle normallik analizi yapılmıştır. Toplanan verilerin normallik dağılımına uygun olması dolayısıyla analizlerde parametrik testler kullanılmıştır. Değişkenler arasındaki anlamlı farklılığın değerlendirilmesinde ikili gruplarda bağımsız örneklem t-Testi, ikiden fazla grup içeren değişkenlerde ise One Way Anova Testi yapılmıştır.

\section{BULGULAR}

Bu bölümde katılımcıların demografik özelliklerinin ve Covid-19 aşısına ilişkin görüşlerinin dağılımlarına ve araştırma sorularını değerlendirmeye yönelik istatiksel analizlere yer verilmiştir.

Tablo 1. Katılımcıların demografik dağılımı.

\begin{tabular}{|c|c|c|}
\hline Değişkenler & \multirow{2}{*}{$\mathbf{n}$} & \multirow{2}{*}{$\%$} \\
\hline Cinsiyet & & \\
\hline Kadın & 315 & 60,9 \\
\hline Erkek & 202 & 39,1 \\
\hline \multicolumn{3}{|l|}{ Yaş } \\
\hline $21-40$ yaş aralığ 1 & 358 & 69,2 \\
\hline $41-56$ yaş aralığı & 159 & 30,8 \\
\hline \multicolumn{3}{|l|}{ Medeni Hal } \\
\hline Evli & 331 & 64,0 \\
\hline Bekar & 186 & 36,0 \\
\hline \multicolumn{3}{|l|}{ Meslek } \\
\hline Öğretmen & 270 & 52,2 \\
\hline Sağlık çalışanı & 247 & 47,8 \\
\hline
\end{tabular}


Araştırmaya katılan bireylerin \%60,9'u kadın iken \%39,1'i erkektir. Katılımcıların yaş dağılımı iki gruba ayrılarak değerlendirilmiş olup büyük çoğunluğun $(\% 69,2)$ 21-40 yaş aralığında olduğu belirlenmiştir. Katılımcı grubunun \%36'sı bekardır. Meslek değişkeni bakımından ise katılımcı oranlarının birbirine yakın değerler aldığı görülmektedir.

Tablo 2. Covid-19 ve Covid-19 aşısına ilişkin değerlendirmelerin dă̆ğlımı.

\begin{tabular}{|c|c|c|c|c|}
\hline \multirow{2}{*}{$\begin{array}{c}\text { Değişkenler } \\
\text { Covid-19'a yakalanma durumu } \\
\end{array}$} & \multicolumn{2}{|c|}{ Öğretmen } & \multicolumn{2}{|c|}{$\begin{array}{l}\text { Sağlık } \\
\text { Çalışanı }\end{array}$} \\
\hline & $\mathbf{n}$ & $\%$ & $\mathrm{n}$ & $\%$ \\
\hline Yakalanan & 44 & 16,3 & 99 & 40,1 \\
\hline Yakalanmayan & 226 & 83,7 & 148 & 59,9 \\
\hline Toplam & 270 & 100 & 247 & 100 \\
\hline \multicolumn{5}{|l|}{ Aș1 olma durumu } \\
\hline Aşı olan & 182 & 67,4 & 213 & 86,2 \\
\hline Olmayı düşünen & 42 & 15,5 & 11 & 4,5 \\
\hline Olmayı düşünmeyen & 46 & 17,1 & 23 & 9,3 \\
\hline Toplam & 270 & 100 & 247 & 100 \\
\hline \multicolumn{5}{|l|}{ Aşı olma/olmayı isteme nedenleri } \\
\hline Ücretsiz olması & 24 & 10,7 & 30 & 13,4 \\
\hline Koruyucu olması & 123 & 54,9 & 137 & 61,16 \\
\hline Etkili olması & 83 & 37,0 & 99 & 44,2 \\
\hline Covid-19'un ciddi bir hastalık olması & 128 & 57,1 & 152 & 67,9 \\
\hline Kendini korumak & 141 & 62,9 & 152 & 67,9 \\
\hline Çevremdekileri korumak & 128 & 57,1 & 144 & 64,3 \\
\hline Aşı olmanın zorunluluk haline gelmesi & 32 & 14,3 & 29 & 12,9 \\
\hline Aşı olmamanın hayatını sınırlandırması & 49 & 21,9 & 20 & 8,9 \\
\hline Çalıştı̆ı kurumun aşı olunmasını talep etmesi & 13 & 5,8 & 16 & 7,1 \\
\hline Toplam & 224 & 100 & 224 & 100 \\
\hline \multicolumn{5}{|l|}{ Olunan/Olunmayı düşünülen aşı türü } \\
\hline Aş1 olmayı düşünmeyen & 46 & 17,0 & 23 & 9,3 \\
\hline Sinovac & 67 & 24,8 & 148 & 59,9 \\
\hline BioNTech & 157 & 58,1 & 76 & 30,8 \\
\hline Toplam & 270 & 100 & 247 & 100 \\
\hline \multicolumn{5}{|l|}{ Aşı olmama nedenleri } \\
\hline Koruyuculuğuna inanmama & 29 & 63,0 & 14 & 60,9 \\
\hline Covid-19'a yakalanmayacağını düşünme & 1 & 2,2 & 3 & 13,0 \\
\hline Aşı alerjisinin olması & 1 & 2,2 & 2 & 8,7 \\
\hline Yan etkilerinden korkma & 39 & 84,8 & 15 & 65,2 \\
\hline Aşı sırasının gelmemesi & 3 & 6,5 & 0 & 0 \\
\hline Yerli aşının üretilmesini bekleme & 3 & 6,5 & 3 & 13,0 \\
\hline Diğer & 5 & 10,9 & 1 & 4,3 \\
\hline Toplam & 46 & 100 & 23 & 100 \\
\hline
\end{tabular}

Araştırmaya katılan öğretmenlerin \%16,3'ü Covid-19'a yakalanmışken sağlık çalışanlarının ise yarısına yakını $(\% 40,1)$ yakalanmıştır. Katılımcıların aşı olma durumları açısından birbirlerine yakın oranlara sahip olduğu görülmekle birlikte araştırmaya katılan sağlık çalışanlarının büyük çoğunluğunun $(\% 86,2)$ aşı olduğu anlaşılmaktadır. Aşı olmayı düşünmeyen bireylerin oranı ise öğretmenlerde $\% 17,1$, sağlık çalışanlarında $\% 9,3$ 'tür. 
Araştırmaya katılan bireylerden 448'i aşı olmuş/olmayı düşünen durumdadır. Birden fazla seçeneğin tercih edilebildiği değişkende, katılımcıların aşı olma/olmayı düşünme durumunu etkileyen faktörlerin dağılımı incelendiğinde her iki grubun da en fazla kendini korumak amacıyla aşı olduğu/olmayı düşündüğü belirlenmiştir. Bu durum üzerinde Covid-19'u ciddi bir hastalık olarak görmelerinin ve çevrelerindeki bireyleri korumak istemelerinin etkili olduğu tespit edilmiştir. En az etkili olan durumun ise çalışılan kurumun aşı olunmasını talep etmesi ve Covid-19'un bireylerin hayatını sınırlandırması olduğu saptanmıştır.

Olunan/olmayı düşünülen aşı çeşidinin öğretmenlerde BioNTech (\%58,1), sağlık çalışanlarında ise Sinovac $(\% 59,9)$ olduğu görülmektedir. Birden fazla seçeneğin tercih edilebildiği aşı olmayı düşünmeme nedenlerine bakıldığında katılımcıların büyük çoğunluğunun aşının yan etkilerinden korktuğu ve aşının koruyucu olduğuna inanmadıkları anlaşılmaktadır.

Tablo 3. Aşı tercihinde etkili olan değişkenlerin dağılımı.

\begin{tabular}{|c|c|c|c|c|c|c|c|c|}
\hline \multirow{3}{*}{ Değişkenler } & \multicolumn{4}{|c|}{ Sinovac } & \multicolumn{4}{|c|}{ BioNTech } \\
\hline & \multicolumn{2}{|c|}{$\begin{array}{l}\text { Sağlık } \\
\text { Çalışanı }\end{array}$} & \multicolumn{2}{|c|}{ Öğretmen } & \multicolumn{2}{|c|}{$\begin{array}{l}\text { Sağlık } \\
\text { Çalışanı }\end{array}$} & \multicolumn{2}{|c|}{ Öğretmen } \\
\hline & $\mathrm{n}$ & $\%$ & $\mathrm{n}$ & $\%$ & $\mathrm{n}$ & $\%$ & $\mathrm{n}$ & $\%$ \\
\hline $\begin{array}{l}\text { Daha güvenilir } \quad \text { olduğunu } \\
\text { düşünüyorum. }\end{array}$ & 31 & 13,8 & 19 & 8,5 & 61 & 27,2 & 90 & 40,2 \\
\hline $\begin{array}{l}\text { Daha koruyucu } \\
\text { düşünüyorum. }\end{array}$ & 17 & 7,6 & 5 & 2,2 & 56 & 25,0 & 102 & 45,5 \\
\hline $\begin{array}{l}\text { Yan etkilerinin daha az olduğunu } \\
\text { düşünüyorum. }\end{array}$ & 46 & 20,5 & 40 & 17,8 & 39 & 17,4 & 13 & 5,8 \\
\hline $\begin{array}{l}\text { Çevremdekilerin tavsiyesinden dolayı } \\
\text { bu aşıy tercih ettim. }\end{array}$ & 6 & 2,7 & 7 & 3,1 & 38 & 16,7 & 37 & 16,5 \\
\hline $\begin{array}{l}\text { Aşı üreticisinin Türk olması bu aşıyı } \\
\text { tercih etmemde etkili oldu. }\end{array}$ & 0 & 0 & 0 & 0 & 31 & 13,8 & 20 & 8,9 \\
\hline $\begin{array}{l}\text { Bu aşının etkisinin daha uzun süreli } \\
\text { olduğunu düşünüyorum. }\end{array}$ & 4 & 1,8 & 0 & 0 & 35 & 16,5 & 54 & 24,1 \\
\hline $\begin{array}{l}\text { Bazı ülkelere girişte diğer aşının kabul } \\
\text { edilmemesinden dolayı bu aşıyı tercih } \\
\text { ettim. }\end{array}$ & 3 & 1,3 & 1 & 0,44 & 6 & 2,7 & 33 & 14,7 \\
\hline Başka aşı tercihinin olmaması & 74 & 33,0 & 14 & 6,25 & 3 & 1,3 & 3 & 1,3 \\
\hline Toplam & 224 & 100 & 244 & 100 & 224 & 100 & 224 & 100 \\
\hline
\end{tabular}

Katılımcıların aşı tercihlerinin nedenlerine ilişkin bulgular Tablo 3'teki gibidir. Bu bulgulara göre, sağlık çalışanlarının Sinovac aşısını tercih etmelerindeki en büyük etkenin başka aşı seçeneğinin olmaması (\%33) olduğu görülmektedir. Bu durumun BioNTech aşısı açısından bulgulara bakıldığında diğer etkenlere göre en az etkiye sahip olduğu tespit edilmiştir $(\% 1,3)$. Her iki meslek grubunda da Sinovac aşısının tercih edilme nedenleri arasında bu aşınının yan etkilerinin daha az olduğu yönündeki değerlendirmelerinin etkili olduğu görülmektedir. Diğer taraftan her iki meslek mensubunun da BioNTech aşısını daha güvenilir ve daha koruyucu bulduğu, çevrelerindeki kişilerin BioNTech aşısını ağırlıklı olarak tavsiye ettiği ve bu aşının etkilerinin daha uzun süreli olduğu yönünde görüş belirttikleri belirlenmiştir. 
Tablo 4. Sağlık İnanç Modeli boyutlarının meslek değişkenine göre analizi.

\begin{tabular}{|c|c|c|c|c|c|c|}
\hline Ölçek Boyutlanı & $\begin{array}{c}\text { Meslek } \\
\text { Değişkeni }\end{array}$ & $\mathbf{n}$ & Ort. & Stan. Sapma & $\mathbf{t}$ & p \\
\hline \multirow[t]{2}{*}{ Duyarlılık Algısı } & Öğretmen & 270 & 3,288 & 0,766 & \multirow{2}{*}{0,764} & \multirow{2}{*}{0,445} \\
\hline & Sağlık Çalışanı & 247 & 3,337 & 0,673 & & \\
\hline \multirow[t]{2}{*}{ Ciddiyet Algisı } & Öğretmen & 270 & 3,679 & 0,993 & \multirow{2}{*}{$-0,309$} & \multirow{2}{*}{0,758} \\
\hline & Sağlık Çalışanı & 247 & 3,654 & 0,896 & & \\
\hline \multirow[t]{2}{*}{ Algılanan Yarar } & Öğretmen & 270 & 3,372 & 1,019 & \multirow{2}{*}{$-0,083$} & \multirow{2}{*}{0,934} \\
\hline & Sağlık Çalışanı & 247 & 3,365 & 0,911 & & \\
\hline \multirow[t]{2}{*}{ Algilanan Engel } & Öğretmen & 270 & 2,232 & 0,789 & \multirow{2}{*}{$-2,570$} & \multirow{2}{*}{$0,01^{*}$} \\
\hline & Sağlık Çalışanı & 247 & 2,058 & 0,743 & & \\
\hline \multirow{2}{*}{$\begin{array}{l}\text { Eyleme Yönelik } \\
\text { İpucu }\end{array}$} & Öğretmen & 270 & 2,565 & 1,041 & \multirow{2}{*}{1,467} & \multirow{2}{*}{0,143} \\
\hline & Sağlık Çalışanı & 247 & 2,705 & 1,134 & & \\
\hline
\end{tabular}

Sağlık İnaç Modeli alt boyutlarının meslek grubu değişkenine göre anlamlı bir farklılık gösterip göstermediğinin belirlenmesinde bağımsız örneklem t-testi yapılmıştır. Analiz sonuçlarına göre ölçek alt boyutlarından sadece algılanan engel alt boyutunun meslek değişkenine göre farklılık oluşturduğu görülmektedir $(p<0,05)$. Verilerin ortalama değerleri incelendiğinde öğretmenlerin algıladığı engel durumunun sağlık çalışanlarına göre daha yüksek olduğuna ulaşılmıştır. Diğer alt boyutlarda farklılık görülmemekle birlikte boyut ortalamaları bakımından her iki meslek grubuna göre Covid-19 duyarlılığı ve Covid-19 aşısına ilişkin yarar algısının orta düzeyde olduğu; Covid-19'u ciddiye alma durumunun yüksek olduğu; Covid-19 aşısı olmaya ilişkin engel algısının ise düşük olduğu tespit edilmiştir. Diğer taraftan Covid-19 aşısı olmaya ilişkin ipuçlarının sağlık çalışanlarında orta düzeyde, öğretmenlerde ise düşük düzeyde olduğu belirlenmiştir. $\mathrm{H}_{1 a}, \mathrm{H}_{1 \mathrm{~b}}, \mathrm{H}_{1 c}$ ve $\mathrm{H}_{1 e}$ araştırma sorularına ilişkin anlamlı farklılık olmadığı $\mathrm{H}_{1 \mathrm{~d}}$ araştırma sorusuna ilişkin ise anlamlı farklılık olduğu anlaşılmıştır.

Tablo 5. Sağglı İnanç Modeli boyutlarının Covid-19'a yakalanma durumuna göre analizi.

\begin{tabular}{|c|c|c|c|c|c|c|}
\hline Ölçek Boyutları & $\begin{array}{l}\text { Covid-19'a } \\
\text { Yakalanma Durumu }\end{array}$ & $\mathbf{n}$ & Ort. & $\begin{array}{l}\text { Stand. } \\
\text { Sapma }\end{array}$ & $\mathbf{t}$ & p \\
\hline \multirow{2}{*}{$\begin{array}{l}\text { Duyarlılık } \\
\text { Alg1sı }\end{array}$} & Yakalanan & 143 & 3,382 & 0,701 & \multirow{2}{*}{1,369} & \multirow{2}{*}{0,171} \\
\hline & Yakalanmayan & 374 & 3,284 & 0,729 & & \\
\hline \multirow[t]{2}{*}{ Ciddiyet Algısı } & Yakalanan & 143 & 3,675 & 0,853 & \multirow{2}{*}{0,119} & \multirow{2}{*}{0,906} \\
\hline & Yakalanmayan & 374 & 3,664 & 0,982 & & \\
\hline \multirow[t]{2}{*}{ Algılanan Yarar } & Yakalanan & 143 & 3,338 & 0,949 & \multirow{2}{*}{$-0,456$} & \multirow{2}{*}{0,648} \\
\hline & Yakalanmayan & 374 & 3,381 & 0,976 & & \\
\hline \multirow[t]{2}{*}{ Algılana Engel } & Yakalanan & 143 & 2,230 & 0,759 & \multirow{2}{*}{1,492} & \multirow{2}{*}{0,136} \\
\hline & Yakalanmayan & 374 & 2,117 & 0,775 & & \\
\hline \multirow{2}{*}{$\begin{array}{l}\text { Eyleme Yönelik } \\
\text { İpucu }\end{array}$} & Yakalanan & 143 & 2,753 & 1,177 & \multirow{2}{*}{1,480} & \multirow{2}{*}{0,140} \\
\hline & Yakalanmayan & 374 & 2,286 & 1,050 & & \\
\hline
\end{tabular}

Tablo 5'te Sağlık İnanç Modeli boyutlarının Covid-19'a yakalanma durumuna göre anlamlı bir farklılık oluşturup oluşturmadığının belirlenmesinde kullanılan t-Testi analiz sonuçlarına yer verilmiştir. Gerçekleştirilen analiz sonucunda hiçbir boyuta ilişkin algının Covid-19'a yakalanma durumuna göre farklılaşmadığ 1 tespit edilmiştir ( $>>0,05)$. Bu bağlamda $\mathrm{H}_{1 \mathrm{f}}, \mathrm{H}_{1 g}$, $\mathrm{H}_{1 \mathrm{~h}}, \mathrm{H}_{1}$ ve $\mathrm{H}_{1 \mathrm{i}}$ araştırma sorularına ilişkin analizlerin anlamlı olmadığ 
birlikte boyutların ortalama değerlerine göre yapılan incelemede Covid-19'a yakalanan bireylerin Covid-19 duyarlılığının, Covid-19'u ciddiye alma durumunun, Covid-19 aşısı olmaya ilişkin algılarının Covid-19'a yakalanmayanlara göre daha yüksek olduğu tespit edilmiştir. Covid-19 aşısı olmaya ilişkin algılanan engel durumu ve aşı olmaya ilişkin ipuçlarının ise Covid-19'a yakalanmayan bireylerde daha yüksek olduğu bulunmuştur.

Tablo 6. Sağlık Inanç Modeli boyutlarının Covid-19 aşısı olma durumuna göre analizi.

\begin{tabular}{|c|c|c|c|c|c|c|}
\hline $\begin{array}{c}\text { Ölçek } \\
\text { Boyutları }\end{array}$ & Aşı Olma Durumu & $\mathbf{N}$ & Ort. & $\begin{array}{l}\text { Stan. } \\
\text { Sapma }\end{array}$ & $\mathbf{F}$ & $\mathrm{p}$ \\
\hline \multirow{3}{*}{$\begin{array}{l}\text { Duyarlılık } \\
\text { Algisı }\end{array}$} & Aşı olan & 395 & 3,379 & 0,688 & \multirow[t]{3}{*}{13,817} & \multirow[t]{3}{*}{$0,000^{*}$} \\
\hline & Olmayı düşünen & 54 & 3,345 & 0,749 & & \\
\hline & Olmayı düşünmeyen & 68 & 2,893 & 0,769 & & \\
\hline \multirow{3}{*}{$\begin{array}{l}\text { Ciddiyet } \\
\text { Algısı }\end{array}$} & Aşı olan & 395 & 3,750 & 0,903 & \multirow[t]{3}{*}{9,786} & \multirow[t]{3}{*}{$0,000^{*}$} \\
\hline & Olmayı düşünen & 54 & 3,639 & 0,980 & & \\
\hline & Olmayı düşünmeyen & 68 & 3,209 & 1,051 & & \\
\hline \multirow{3}{*}{$\begin{array}{l}\text { Algilanan } \\
\text { Yarar }\end{array}$} & Aşı olan & 395 & 3,561 & 0,842 & \multirow[t]{3}{*}{72,766} & \multirow[t]{3}{*}{$0,000^{*}$} \\
\hline & Olmayı düşünen & 54 & 3,432 & 0,968 & & \\
\hline & Olmayı düşünmeyen & 68 & 2,205 & 0,844 & & \\
\hline \multirow{3}{*}{$\begin{array}{l}\text { Algilanan } \\
\text { Engel }\end{array}$} & Aşı olan & 395 & 2,015 & 0,713 & \multirow[t]{3}{*}{29,893} & \multirow[t]{3}{*}{$0,000^{*}$} \\
\hline & Olmayı düşünen & 54 & 2,435 & 0,873 & & \\
\hline & Olmayı düşünmeyen & 68 & 2,698 & 0,716 & & \\
\hline \multirow{3}{*}{$\begin{array}{l}\text { Eyleme } \\
\text { Yönelik İpucu }\end{array}$} & Aş1 olan & 395 & 2,807 & 1,046 & \multirow[t]{3}{*}{38,440} & \multirow[t]{3}{*}{$0,000^{*}$} \\
\hline & Olmayı düşünen & 54 & 2,605 & 0,956 & & \\
\hline & Olmayı düşünmeyen & 68 & 1,637 & 0,880 & & \\
\hline
\end{tabular}

Covid-19 aşısı olma durumu ile Covid-19'a ilişkin duyarlılık ve ciddiyet algısının; Covid-19 aşısına ilişkin yarar, engel ve ipuçlarının değerlendirilmesinde One Way Anova Testi yapılmıştır. Yapılan analiz Sağlık İnanç Modelinin tüm boyutları bakımından $\mathrm{H}_{1 \mathrm{j}}, \mathrm{H}_{1 \mathrm{k}}, \mathrm{H}_{11}, \mathrm{H}_{1 \mathrm{~m}}$ ve $\mathrm{H}_{1 n}$ araştırma sorularına ilişkin yapılan analiz sonuçlarında değişkenler bakımından anlamlı faklılık olduğu doğrulanmıştır $(p<0,05)$.

Analiz sonuçlarına göre Covid-19 aşısı olan ve aşı olmayı düşünen bireylerin aşı olmayı düşünmeyen bireylere göre Covid-19 hastalığına ilişkin duyarlılıklarının, ciddiyet algılarının, Covid-19 aşısına ilişkin yarar algılarının ve aşı olmaya ilişkin ipuçlarının daha yüksek olduğu belirlenmiştir. Diğer tarftan aşı olmaya ilişkin algılanan engel durumunun ise aşı olmayı düşünmeyen bireylerde diğer gruplardaki bireylere göre daha yüksek olduğu tespit edilmiştir.

\section{TARTIŞMA}

Covid-19 salgını, sosyal ve ekonomik sistem üzerinde ciddi etkiler oluşturmuştur. Bu etkilerle birlikte milyonlarca kişinin hastalanmasına ve ölümüne neden olmuştur. Bu sorunlar hala devam etmektedir ve ne zaman sonlanacağına ilişkin bir netlik bulunmamaktadır. Bununla birlikte aşı uygulamalarının toplumda yaygınlaşması, salgının sonlandırılmasında en etkili yollardan biri olarak görülmektedir (Lazarus vd., 2021). Ancak aşılanma oranları ülkemizde hala istenilen düzeyde değildir. Bunun nedenlerinin tespit edilerek gerekli önlemlerin alınması salgının ülkemizdeki etkilerinin azaltılmasında ve sonlandırılmasında son derece önemlidir. $\mathrm{Bu}$ araştırma ile toplumun kararlarında etkili olan ve toplumu yönlendiren, günlük hayatta birçok kişi ile etkileşim halinde olan sağlık çalışanlarının ve öğretmenlerin Covid-19 
hastalığına ilişkin algıları, Covid-19 aşılarına ilişkin düşünceleri, aşı tercihlerini etkileyen unsurlar ve aşı yaptırmama nedenleri belirlenmeye çalışılmıştır.

Meslek değişkenine göre katılımcıların Covid-19 hastalığına yakalanma durumları arasındaki oransal farklılık; salgın dönemi içerisinde öğretmenlerin genel olarak uzaktan eğitim gerçekleştirmeleri, yüz yüze eğitime ara verilmiş olunması ve sağlık çalışanlarının daha aktif bir dönem içerisinde olmaları, Covid-19 tehlikesine maruz kalma durumlarının daha fazla olması ile açıklanabilir. Bu araştırma bulgusundan farklı olarak Kurtuluş ve Can (2021)'ın çalışmasında toplumun rol model gördüğü sağlık çalışanlarının her ikisinden birinin aşı olmayı kabul etmediği sonucuna ulaşılmıştır. Diğer taraftan Cömert ve Şahin Çakır (2021) da yapmış oldukları çalışmada öğretmenlerin genel olarak tedbirlere uyduğunu ifade etmiştir. Literatürde yer alan diğer çalışmalar ve araştırma bulguları doğrultusunda çeşitli nedenlere bağlı olarak sağlık çalışanlarının öğretmenlere oranla daha fazla Covid-19'a yakalandığı anlaşılmaktadır. Covid-19'a yakalanan sağlık çalışanlarının değerlendirildiği başka bir çalışmada da sağlık çalışanlarına Covid-19 bulaşma riskinin artmış olduğu sonucuna ulaşılmıştır (Eren vd., 2020, s. 233). Bu durumun nedeni olarak salgınla doğrudan mücadele halinde olan sağlık çalışanlarının yeterince korunmadığı, yetersiz kişisel koruyucu ekipman ve hastalığın yayılmasını önlemek için yetersiz hükümet politikalarıyla karşı karşıya bırakıldığı söylenilebilir (Kalra vd., 2020, s. 2937).

Katılımcıların aşı olma durumları açısından birbirlerine yakın oranlara sahip oldukları görülmekle birlikte araştırmaya katılan sağlık çalışanlarının büyük çoğunluğunun $(\% 86,2)$ aşı olduğu anlaşılmaktadır. Aşı olmayı düşünmeyen bireylerin oranı ise öğretmenlerde $\% 17,1$, sağlık çalışanlarında ise \%9,3'tür. Tıp fakültesi son sınıf öğrencilerine yönelik yapılan bir araştırmada katılımcıların \%84,3'ünün ülkemizdeki aşı reddi oranlarının arttığını belirttikleri, toplumdaki rol model olarak nitelendirilebilecek insanların bu konuda olumsuz örnek olmasının, alternatif tıp sempatizanlarının ve bazı bilim insanlarının aşılar hakkındaki açıklamalarının bu durumun nedeni olduğunu düşündükleri sonucuna ulaşılmıştır (Günay vd., 2020).

Araştırmaya katılan bireylerden aşı olanların en fazla Covid-19'u ciddi bir hastalık olarak görmelerinin ve çevrelerindeki bireyleri korumak istemelerinin aşı olmalarında etkili olduğu tespit edilmiştir. En az etkili olan durumun ise çalışılan kurumun aşı olunmasını talep etmesi ve Covid-19'un bireylerin hayatını sınırlandırması yönünde olduğu saptanmıştır. Finlandiya' da yapılan bir araştırma sonucunda bireylerin Covid-19'u ciddi bir hastalık olarak algılayıp başkalarına bulaştırma konusunda endişelendikleri bulgusuna ulaşılmıştır. Bununla birlikte, katılımcıların bir bölümü hastalığın kendi sağlıkları üzerindeki riskinden daha az endişe duyduklarını ve ankete katılanların yaklaşık 3/4'ünün böyle bir aşının bulunması ve yetkililer tarafından tavsiye edilmesi halinde Covid-19 aşısı olacaklarını ifade ettikleri görülmüştür (Karlsson vd., 2021, s. 172).

Olunan/Olunmayı düşünülen aşı çeşidinin öğretmenlerde BioNTech (\%58,1), sağlık çalışanlarında ise Sinovac $(\% 59,9)$ olduğu belirlenmiştir. Bu durum üzerinde BioNTech aşısının ülkemize Sinovac aşısından çok daha sonra gelmiş olması, aşılanan ilk grubunun sağlık çalışanları olması, öğretmenlerin mesleki öncelik grubundan yararlanarak değil de yaş ölçütüne bağlı olarak uzayan bir süreç içerisinde aşı olmuş olmaları gerekçe olarak gösterilebilir. Türkiye'deki Covid-19 aşılamasında öncelikli gruplar arasında sağlık kurumlarında çalışanların, kamu, özel, üniversite, vakıf, tıp ve diş fakültesi stajyer öğrenciler 
dahil tüm kamu serbest eczane çalışanlarının (eczacı, kalfa dahil) yer aldığı görülmektedir (Yıldırım Baş, 2021, s. 248).

Aşı olmayı düşünmeyen bireylerin gerekçeleri değerlendirildiğinde, katılımcların büyük çoğunluğunun aşının yan etkilerinden korktuğu ve aşının koruyucu olduğuna inanmadıkları anlaşılmaktadır. Toplumsal algının, aşı olmuş olan vatandaşların aşı sonrasıdaki olumsuz değerlendirmelerinin, vatandaşlar arasındaki söylentilerin, aşının koruyuculuğuna dair medyada yer alan olumsuz içerikli yayınların böyle bir yaklaşıma sebep olduğu düşünülebilir. ABD'de Covid-19 aşısına ilişkin toplumun tutumlarını, değerlerini ve niyetlerini belirlemek için bir çalışma yapılmış olup bu çalışmada katılımcıların \%44'ünün aşıların içeriğiyle ilgili endişeleri olduğu sonucuna ulaşılmıştır (Salmon vd., 2021, s. 2702). Ürdün'de Covid-19 aşılarına ilişkin toplumun tutumunu belirlemek üzere gerçekleştirilen çalışmada Covid-19 hastalığının bir komplo olduğunu düşünenlerde ve aşıyı güvenilir bulmayanlarda aşının kabul edilebilirliğinin daha düşük olduğu belirlenmiştir (El-Elimat vd., 2021, s. 1). Diğer taraftan hiçbir aşının \%100 etkili olmamasıyla birlikte hastalığın şiddetini veya bulaşma riskini azalttığı ve aşıların hastalığa karşı belirli bir süre koruma sağladığı ifade edilebilir. Bu nedenle kişilerin aşılanmaları son derece önemlidir. Aşıların \%100 etkili olmaması nedeniyle aşılanmış kişilerin de kendilerini ve başkalarını korumak için tüm tedbirleri, yönergeleri takip etmeye devam etmeleri gerekmektedir (Cohn ve Mbaeyi, 2020, s. 26). Ayrıca Küçükali ve Çınar (2020), akademisyenlere yönelik gerçekleştirdikleri çalışmalarında akademisyenlerin bu salgının küresel akıllarca tasarlanmış ve ileride devam edecek biyolojik saldırılardan biri olabileceğine yönelik bir algıya sahip olduklarını belirlemişlerdir. Bu durumun da bireylerin aşı olmayı reddetmelerinde bir etken olabileceği ifade edilebilir.

Katılımcıların aşı tercihlerinin nedenlerine yönelik bulgulara göre, sağlık çalışanlarının Sinovac aşısını tercih etmelerindeki en büyük etkenin başlangıç olarak başka aşı seçeneğinin olmaması olduğu görülmektedir. Her iki meslek grubu çalışanlarının BioNTech aşısını daha güvenilir ve daha koruyucu bulmakla birlikte Sinovac aşısını tercih etmelerindeki en büyük etken olarak ise bu aşınının yan etkilerinin daha az olduğuna yönelik bakış açısı olduğu anlaşılmaktadır. Civelek vd. (2021) de yaptıkları araştırmada doktorların aşıların etkinliğine odaklanma eğiliminde olduklarını, Türk hekimleri arasında belirli bir aşının tercihini etkileyen en önemli faktörün ise güvenlik olduğunu belirlemişlerdir. Başka bir çalışmada da COVID-19 aşısı yaptırma niyetinin yüksek olmasının en güçlü yordayıcısının aşının güvenilirliği olduğu ifade edilmiştir (Karlsson vd., 2021, s. 172). Bu bağlamda araştırma bulguları ile literatürde yer alan diğer çalışmalarının sonuçlarının benzer nitelikte olduğu anlaşılmaktadır.

Sağlık İnaç Modeli alt boyutlarının meslek grubu değişkenine göre verilerin ortalama değerleri incelendiğinde öğretmenlerin algıladığı engel durumunun sağlık çalışanlarına göre daha yüksek olduğu belirlenmiştir. Covid-19 aşısı olmaya ilişkin ipuçlarının sağlık çalışanlarında orta düzeyde, öğretmenlerde ise düşük düzeyde olduğu görülmüştür. Literatüre bakıldığında Korkmaz vd., (2021)'nin kişisel koruyucu ekipman kullanımını SiM ile inceledikleri çalışmalarında hekimlerin Covid-19'u diğer gruplara göre daha düşük düzeyde tehdit olarak algıladıkları sonucuna ulaşmışlardır. Amerika'da tıp öğrencileriyle yapılan bir çalışmada da neredeyse tüm katılımcıların aşılara karşı olumlu tutumları olduğu ve Covid-19'a maruz kalacakları konusunda hemfikir oldukları saptanmıştır (Lucia vd., 2020, s. 2). Bununla birlikte Türkiye'de yapılan bir çalışmada sağlık uzmanlarının yaklaşık \%84,6'sının mümkün olduğunca Covid-19 aşısını kabul etmeye istekli oldukları beyanına ulaşılmıştır (Kaplan vd., 
2021, s. 3). Kaya vd. (2021) ise araştırmaları sonucunda öğretmenlerin salgına yönelik bireysel hazırlık algı düzeylerinin yüksek olduğu sonucuna varmışlardır. Bu bağlamda araştırma sonuçlarının literatürdeki benzer çalışmalarla uyumlu olduğu söylenilebilir.

Sağlık İnanç Modeli boyutlarının Covid-19'a yakalanma durumuna göre anlamlı bir farklılık oluşturup oluşturmadığının belirlenmesinde hiçbir boyuta ilişkin algının Covid-19'a yakalanma durumuna göre farklılaşmadığı tespit edilmiştir. Covid-19'a yakalanan bireylerin Covid-19 hastalığına yönelik duyarlılıklarının, ciddiye alma durumlarının, aşı olmaya yönelik algılarının Covid-19'a yakalanmayanlara göre daha yüksek olduğu tespit edilmiştir. Uludağ vd. (2020) tarafından serviks kanseri taraması yaptırma durumu SİM ile değerlendirilmiştir. Araştırmada Pap smear testi yaptırmama nedeni ile algılanan engel düzeyi arasında anlamlı bir fark bulunmamıştır. Özoğul ve Sucu Dağ (2019) tarafından meme kanserinin erken teşhisinde sağlı inançlarını etkileyen faktörlerin belirlenmesi amacıyla gerçekleştirilen çalışmada ailelerinde kanser öyküsü bulunan kadınların duyarlılık düzeylerinin olmayan kadınlara göre daha yüksek olduğu bulunmuştur. Ding vd. (2020), Çin'de yaptıkları araştırmada, düşük risk algısına sahip kişilerin riskli davranışlarda bulunma veya önleyici davranışları azaltma eğiliminde; yüksek risk algısına sahip kişilerin ise önleyici davranış sergileme eğiliminde olabilecekleri belirtilmiştir. Bal (2014) tarafından SIMM ile kadınların pap smear testi yaptırma durumlarını değerlendirdikleri çalışmada katılımcıların duyarlılık ve ciddiyet algısının hiçbir değişkenden etkilenmediği belirlenmiştir. Algılanan yarar durumunun ise smear testini bilen kişilerde daha yüksek olduğu tespit edilmiştir. Olgun ve Altun (2012) tarafından diyabet hastalarının kendi kendilerine bakım uygulamalarının değerlendirilmesinde sağlık inanç modeli kullanılmıştır. Diyabetle ilgili bilgi düzeyi yüksek olan kişilerin sağlık inançları da yüksek bulunmuştur. Literatürdeki diğer çalışmalar da dikkate alındığında Covid-19 hastalığını deneyimleyen kişilerin hastalığın seyri, ciddiyeti ve semptomlarıyla ilgili bilgi düzeylerinin arttı̆̆ı ve bunun sağlık inanç modeli alt boyutlarında yer alan değişkenlere ilişkin farkındalıklarını arttırdığı söylenilebilir.

Covid-19 aşısı olmaya ilişkin algılanan engel durumu ve aşı olmaya ilişkin ipuçları ise Covid19'a yakalanmayan bireylerde daha yüksektir. Bu durum üzerinde ise Covid-19 hastalığının deneyimlenilmemiş olmasına bağlı olarak hastalığın ciddiyetinin farkına varılmamış olunması gerekçe olarak gösterilebilir. Literatürde bireylerin aşı olma durumunu etkileyen faktörlerle ilgili yapılan çalışmalara bakıldığında farklı değişkenlerin değerlendirildiği görülür. Bunlardan El- Elimat vd. (2021)'in Ürdün'de yürütmüş oldukları çalışmada, mevsimsel grip aşısı olanların Covid-19 aşısını kabul etme oranlarının daha yüksek olduğu tespit edilmiştir. Malik vd. (2020) ise Amerikada Covid-19 aşısının kabul edilme durumunu değerlendirdikleri çalışmada, liseyi bitirmemiş katılımcıların, işsiz katılımcıların ve siyah Amerikalıların aşı kabul oranlarının daha düşük olduğu saptanmıştır. Başka bir çalışmada da yaşlı bireylerin genç bireylere göre aşı olma isteklilikleri daha yüksek bulunmuştur (Lazarus vd., 2021, s. 225). Bu araştırmada ise Covid-19'a yakalanmama durumunun katılımcıların engel algısını arttırdığı, diğer taraftan bu bireylerin aşı olma istekliliğinin de yüksek olduğu ifade edilebilir.

\section{SONUÇ VE ÖNERİLER}

Tüm dünyada aşılanma oranının arttırılması için aşı reddine sebep olan durumların tespit edilerek gerekli önlemlerin alınması, salgının etkilerinin azaltılmasında ve sonlandırılmasında son derece önemlidir. Bu araştırma ile toplumun alacağı kararlarda etkili olan ve toplumu yönlendiren, günlük hayatta birçok kişi ile etkileşim halinde olan sağlık çalışanlarının ve 
öğretmenlerin Covid-19 hastalığına ilişkin algıları, Covid-19 aşılarına ilişkin düşünceleri, aşı tercihlerini etkileyen unsurlar ve aşı yaptırmama nedenleri belirlenmeye çalışılmıştır. Araştırma sonucunda aşı olan/olmayı düşünen bireylerin aşı olma kararlarında en fazla etkili olan faktörün Covid-19'u ciddi bir hastalık olarak görmelerinin ve çevrelerindeki bireyleri korumak istemelerinin etkili olduğu anlaşılmıştır. Katılımcıların aşı tercihinde ise aşının güvenilirliğinin, koruyuculuğunun ve yan etkilerinin az olmasının en etkili faktörler olduğu belirlenmiştir. Ayrıca araştırma kapsamında belirlenen ve aşı reddine neden olan en önemli unsurun ise aşının yan etkilerinden korkma ve aşının koruyucu olmadığına inanma olduğu sonucuna ulaşılmıştır. Bu bağlamda aşılanma oranlarının arttırılmasında toplumun aşıların koruyuculuğu, güvenirliliği ve yan etkileriyle ilgili olumsuz algılarının giderilmesinin etkili olacağı söylenilebilir. Bunun sağlanabilmesi için daha kanıtlayıcı ve aydınlatıcı bilgilerin verilmesi gerektiği ifade edilebilir.

Aşı olan ve aşı olmayı düşünen bireylerin Covid 19'a ilişkin duyarlılıklarının, hastalığı ciddiye alma durumlarının, aşıyı yararlı bulma durumlarının ve aşı olmayla ilgili eyleme yönelik ipuçlarının daha yüksek olduğu belirlenmiştir. Diğer taraftan aşı olan ve olmayı düşünen bireylerin algılanan engel durumlarının daha düşük olduğu sonucuna ulaşılmıştır. Bu bağlamda katılımcıların Covid-19 ve Covid-19 aşılarına ilişkin algılarının aşı olma davranışı üzerinde önemli bir etken olduğu anlaşılmaktadır. Bu nedenle aşılara ilişkin olumsuz algının giderilmesinin ve daha fazla bilgilendirme yapılmasının aşılanma oranlarının arttrılmasında son derece önemli olduğu söylenilebilir.

\section{KAYNAKÇA}

Aydoğar Takcı, M. \& Yıldırım, G. (2021). Diyabet hastalarına Sağlık İnanç Modeli doğrultusunda verilen eğitimin sağlık inancına, öz etkililik algısına ve karar verme düzeyine etkisi. Mersin Üniversitesi Tıp Fakültesi Lokman Hekim Tıp Tarihi ve Folklorik Tıp Dergisi, 11(1), 73-82.

Aykaç Koçak, A. \& Tümer, A. (2022). Öğretmenlerin kolorektal kanserden korunmaya yönelik sağlık inançları . Sağlık Akademisi Kastamonu, 7(1), 3-4.

Bal, M.D. (2014). Kadınların pap smear testi yaptırma durumlarının sağlık inanç modeli ölçeği ile değerlendirilmesi. Marmara Üniversitesi Sağlık Bilimleri Enstitüsü Dergisi, 4(3), 133-138.

Balay, R. (2004). Küreselleşme, bilgi toplumu ve eğitim. Ankara Üniversitesi Ĕ̆itim Bilimleri Fakültesi Dergisi, 37(2), 61-82. https://www.acarindex.com/dosyalar/makale/acarindex1423870027.pdf

Champion, V., L. \& Skinner, C., S. (2008). The health behavior and health education: Theory, research, and practice: The Health Belief Model. (4th ed., pp. 45-62). K. Glanz, K. Rimer, K. Viswanath (Eds.). Jossey-Bass. 
Civelek, B., Yazıc1, O., Özdemir, N., Karacin, C. \& Sürel, A.A. (2021). Attitudes of physicians towards COVID-19 vaccines and reasons of vaccine hesitancy in Turkey. The International Journal of Clinical Practice. https://doi.org/10.1111/ijcp.14399

Cohn, A. \& Mbaeyi, S. (2020). What clinicians need to know about the Pfizer-BioNTech COVID-19 vaccine. https://www.cdc.gov/vaccines/covid-19/downloads/pfizer-biontechvaccine-what-Clinicians-need-to-know.pdf

Cömert, İ. \& Şahin Çakır, Ç. (2021). Covid-19 ile ilgili öğretmen algılarını belirlemeye yönelik bir olgu bilim çalışması. Academia Eğitim Araştırmaları Dergisi, 6(2), 382-405. https://doi.org/10.53506/egitim.905674

Demir, F. \& Özdaş, F. (2020). Covid-19 sürecindeki uzaktan eğitime ilişkin öğretmen görüşlerinin incelenmesi. Milli Ĕ̆itim Dergisi, 49(1), 273-292.

Ding, Y., Du, X., Li, Q., Zhang, M., Tan, X. \& Liu, Q. (2020). Risk perception of coronavirus disease 2019 (COVID-19) and its related factors among college students in China during quarantine. PLoS ONE, 15(8), e0237626. https://doi.org/10.1371/journal.pone.0237626

El- Elimat, T., AbuAlSamen, M., Almomani, B. A., Al-Sawalha, N. A. \& Alali, F. Q. (2021). Acceptance and attitudes toward COVID-19 vaccines: A cross-sectional study from Jordan. PLoS ONE, 16(4), e0250555. https://doi.org/10.1371/journal.pone.0250555

Eren, E., Çelik, İ., Yıldız, M., Topaloğlu, U.S., Kılınç-Toker, A., Arman Fırat, E., Gür, A., Bolat, E. \& Ulu Kılıç, A. (2020). COVID-19 geçiren sağlık çalışanlarının değerlendirilmesi. Klinik Journal, 33(3), 230-234.

Erkin, Ö. (2010). Să̆llk çalışanlarının grip aşısı olma durumları ve gripten korunmaya yönelik să̆lık inanç modeli ölçeğinin geçerlik ve güvenirlik çalışması. Yüksek lisans tezi, Ege Üniversitesi, İzmir.

Görgülü Arı, A. \& Hayır Kanat, M. (2020). Covid-19 (Koronavirüs) üzerine öğretmen adaylarının görüşleri. Yüzüncü Yıl Üniversitesi Sosyal Bilimler Enstitüsü Dergisi, Salgin Hastaliklar Özel Sayısl,

https://dergipark.org.tr/en/pub/yyusbed/issue/56115/772126

459-492.

Gözüm, S. \& Çapık, C. (2014). Sağlık davranışlarının geliştirilmesinde bir rehber: Sağlık inanç modeli. Dokuz Eylül Üniversitesi Hemşirelik Fakültesi Elektronik Dergisi, 7(3), 230-237. https://dergipark.org.tr/tr/pub/deuhfed/issue/46807/586981

Graham, B.S. (2020). Rapid COVID-19 vaccine development. Science, 368, 945-946.

Günay, İ., Tatar, M., Saygılı, M., Yörük, B.G., Başpınar, S. \& Saygun, M. (2020). Tıp fakültesi son sınıf öğrencilerinin ülkemizdeki aşı reddi hakkındaki düşünceleri, Genel Tıp Dergisi, 30(3), 133-139.

Gür, E. (2019). Vaccine hesitancy - vaccine refusal. Türk Pediatri Arşivi, 54(1), 1-2.

Gürbüz, S. \& Şahin, F. (2017). Sosyal bilimlerde araştırma yöntemleri. Seçkin Yayıncılık.

Haleem, A., Javaid, M., \& Vaishya, R. (2020). Effects of COVID-19 pandemic in daily life. $\begin{array}{lllll}\text { Current Medicine Research } & \text { 78-79. }\end{array}$ https://doi.org/10.1016/j.cmrp.2020.03.011 
İbici Akça, E. (2021). Nullipar gebelere Sağlık İnanç Modeli doğrultusunda verilen mobil eğitimin normal doğum eğilimine etkisi. Doktora tezi, İnönü Üniversitesi, Malatya.

Kalra, A., Michos, E.D. \& Chinnaiyan, K.M. (2020). COVID-19 and the healthcare workers. European Heart Journal, 41(31), 2936-2937. https://doi.org/10.1093/eurhearti/ehaa489

Kaplan, A.K., Şahin, M.K., Parildar, H. \& Güvenç, I.A. (2021). The willingness to accept the COVID-19 vaccine and affecting factors among healthcare professionals: A crosssectional study in Turkey. The International Journal of Clinical Practice, 75(7), 1-10.

Karlsson, L.C., Soveri, A., Lewandowsky, S., Karlsson, L., Karlsson, H., Nolvi, S., Karukivi, M., Lindfelt, M. \& Antfolk, J. (2021). Fearing the disease or the vaccine: The case of COVID19. Personality and Individual Differences, 172, 110590. https://doi.org/10.1016/j.paid.2020.110590

Kasap, S. (2020). MEB'in eğitim ordusunda 1 milyonu aşkın öğretmen görev başında. https://www.aa.com.tr/tr/egitim/mebin-egitim-ordusunda-1-milyonu-askin-ogretmengorev-basinda-/2053093

Kaya, A., Moçoşoğlu, B. \& Sevim, H. (2021). Sağlık inanç modeline dayalı olarak öğretmenler ve okul yöneticilerinin salgına yönelik bireysel hazırlık algılarının incelenmesi. OPUS Uluslararası Toplum Araştırmaları Dergisi, 18(40), 2345-2374. https://doi.org/10.26466/opus.868717

Kazak, A., Hintistan, S., \& Önal, B. (2020). Dünyada ve Türkiye'de Covid-19 aşı geliştirme çalışmaları. Celal Bayar Üniversitesi Să̆lık Bilimleri Enstitüsü Dergisi, 7(4), 571-575.

Kırılmaz, H., \& Doğanyiğit, P.B. (2021). Kendi kendine ilaç kullanımı ve Sağlık İnanç Modeli ilişkisi. Süleyman Demirel Üniversitesi Sağlık Bilimleri Dergisi, 12(2), 200-209. https://dergipark.org.tr/en/pub/sdusbed/issue/64440/897506

Korkmaz, S., Bıyık, E., \& Demiralp, G. (2021). Covid-19 salgınından korunmada sağlık çalışanlarında kişisel koruyucu ekipman kullanımı: Sağlık inanç modeli uygulaması. Ankara Hacı Bayram Veli Üniversitesi İktisadi ve İdari Bilimler Fakültesi Dergisi, 23(1), 1-16. https://dergipark.org.tr/en/pub/ahbvuibfd/issue/61592/828330

Kırılmaz H., \& Doğanyiğit P.B. (2021). Kendi kendine ilaç kullanımı ve Sağlık İnanç Modeli ilişkisi. Süleyman Demirel Üniversitesi Sağllk Bilimleri Dergisi, 12(2), 200-209. https://dergipark.org.tr/en/pub/sdusbed/issue/64440/897506

Kurcer, M.A., \& Erdoğan, Z. (2020). Sağlık İnanç Modeline göre sigara birakma ölçeğinin geliştirilmesi. Acıbadem Üniversitesi Sağhlk Bilimleri Dergisi, 11(3), 464-470. https://doi.org/10.31067/0.2020.296

Kurtuluş, Ş. \& Can, R. (2021). What do health care professionals think about Covid-19 vaccine applications: A university example. Harran Üniversitesi Tıp Fakültesi Dergisi, 18(1), 29-34. https://doi.org/10.35440/hutfd.908043

Küçükali, A. \& Çınar, O. (2020). Akademisyenlerin kovid-19 algısı. Atatürk Üniversitesi Sosyal Bilimler Enstitüsü Dergisi, 1633-1654. https://dergipark.org.tr/en/pub/ataunisosbil/issue/59389/808013 
Lazarus, J.V., Ratzan, S.C., Palayew, A., Gostin, L.O., Larson, H.J., Rabin, K., Kimball, S. \& ElMohandes, A.A. (2021). Global survey of potential acceptance of a COVID-19 vaccine. Nature Medicine, 27(2), 225-228. https://doi.org/10.1038/s41591-020-1124-9

Lucia, V.C., Kelekar, A. \& Afonso, N.M. (2020). COVID-19 vaccine hesitancy among medical students. Journal of Public Health, 1-5.

Malik, A.A., McFadden, S.M., Elharake, J., \& Omer, S.B. (2020). Determinants of COVID-19 vaccine acceptance in the US. EClinicalMedicine, 100495. https://doi.org/10.1016/j.eclinm.2020.100495

Olgun, N., \& Altun, Z. A. (2012). Sağlık inanç modeli doğrultusunda verilen eğitimin diyabet hastalarının bakım uygulamalarına etkisi. Hacettepe Üniversitesi Hemşirelik Fakültesi Dergisi, 19(2), 46-57. https://dergipark.org.tr/en/download/article-file/88620

Our World in Data, Coronavirus (COVID-19) vaccinations. https://ourworldindata.org/covidvaccinations? country=OWID WRL

Özoğul, E., \& Sucu Dağ, G. (2019). Üniversitede çalışan kadınların meme kanserinde erken tanıya yönelik sağlık inançları. Dokuz Eylül Üniversitesi Hemşirelik Fakültesi Elektronik Dergisi, 12(4), 264-273. https://dergipark.org.tr/en/download/article-file/831201

Parıldar, H. (2020). Tarihte bulaşıcı hastalık salgınları. Tepecik Eğitim ve Araştırma Hastanesi Dergisi, 30, 19-26.

Sağlık Bakanlığı, (2019). T.C. Sağlik Bakanlığı sağlık istatistikleri yıllığı. https://dosyasb.saglik.gov.tr/Eklenti/40564,saglik-istatistikleri-yilligi-2019pdf.pdf?0

Salmon, D.A., Dudley, M.Z., Brewer, J., Kan, L., Gerber, J.E., Budigan, H., Proveaux, T.M., Bernier, R., Rimal, R. \& Schwartz, B. (2021). COVID-19 vaccination attitudes, values and intentions among United States adults prior to emergency use authorization. Vaccine, 39(19), 2698-2711. https://doi.org/10.1016/j.vaccine.2021.03.034

Uludağ, G., Gamsızkan, Z. \& Sungur, M.A. (2020). Kadınların serviks kanseri ve taraması ile ilgili sağlık inançlarının değerlendirilmesi. Düzce Üniversitesi Sağlık Bilimleri Enstitüsü Dergisi, 10(3), 357-362.

Ülman, Y. I. (2020). COVID-19 enfeksiyon hastalığı salgınına biyoetik açıdan bakış. Acıbadem Üniversitesi Să̆lık Bilimleri Dergisi, (3), 365-371. https://doi.org/10.31067/0.2020.287

Velavan, T.P. \& Meyer, C.G. (2020). The COVID-19 epidemic. Tropical Medicine and International Health, 25(3), 278-280.

Wu, S.C. (2020). Progress and concept for COVID-19 vaccine development. Biotechnol Journal, 15(6), e2000147.

Yavuz, E. (2020). COVID-19 aşıları. Türkiye Aile Hekimliği Dergisi, 24(4), 223-234.

Yıldırım Baş, F. (2021). Pandemide aşılamanın önemi ve Covid 19 aşılama çalışmaları. Süleyman Demirel Üniversitesi Tip Fakültesi Dergisi, COVID-19 Özel Sayı(1), 245-248. https://doi.org/10.17343/sdutfd.902436 